\title{
Regulation of vascular growth and tone by hydrogen sulfide
}

\author{
Andreas Papapetropoulos \\ From 5th International Conference on cGMP: Generators, Effectors and Therapeutic Implications \\ Halle, Germany. 24-26 June 2011
}

Hydrogen sulfide $\left(\mathrm{H}_{2} \mathrm{~S}\right)$ is a colourless, flammable gas with a characteristic pungent smell. Until recently, the $\mathrm{H}_{2} \mathrm{~S}$ literature was focused in the toxicology of this agent. Exposure to $\mathrm{H}_{2} \mathrm{~S}$ concentrations lower than $100 \mathrm{ppm}$ lead to eye irritation, sore throat, dizziness, nausea, shortness of breath, and chest tightness, while exposure to $1000 \mathrm{ppm}$ or more causes central nervous system toxicity and respiratory depression. In the past 5 years the interest for $\mathrm{H}_{2} \mathrm{~S}$ biology has seen an upsurge, as it was accepted that low amounts of this gas are endogenously produced in most mammalian tissues. Increasing evidence shows that $\mathrm{H}_{2} \mathrm{~S}$ acts as a signalling molecule in cells and is now considered the third member of the gasotransmitter family along with nitric oxide and carbon monoxide. Most of $\mathrm{H}_{2} \mathrm{~S}$ is produced by two enzymes cystathionine-synthase (CBS) and cystathionine $\gamma$-lyase (CSE) that use L-cysteine as a substrate and pyridoxal phosphate as a co-factor. CBS is highly expressed in the central nervous system, while CSE is abundantly present in the heart, lung, blood vessels, liver and kidney.

$>$ In the cardiovascular system, $\mathrm{H}_{2} \mathrm{~S}$ has anti-apoptotic effects on cardiomyocytes, exerts cardioprotective actions and modifies vascular tone. We have recently shown that exogenously administered $\mathrm{Na}_{2} \mathrm{~S}$ stimulates endothelial proliferation, migration and capillary-like network formation. These effects of $\mathrm{H}_{2} \mathrm{~S}$ on migration are mediated through the activation of ATP-sensitive $\mathrm{K}^{+}$-channels $\left(\mathrm{K}_{\mathrm{ATP}}\right)$ and activation of mitogen activated protein kinase pathways. Inhibition of CSE and reduction of endogenously produced $\mathrm{H}_{2} \mathrm{~S}$ reduces vascular network length and branching of blood vessels in the chicken chorioallantoic membrane. Exposure of endothelial cells to vascular endothelial growth factor (VEGF) increased $\mathrm{H}_{2} \mathrm{~S}$ production and genetic or pharmacological inhibition of CSE restricted VEGF signalling and VEGF-driven angiogenic responses (migration, sprouting). Thus, $\mathrm{H}_{2} \mathrm{~S}$ is an endogenous activator of angiogenesis and modulation of its production might be useful in diseases characterized by aberrant or excessive angiogenesis.

$\mathrm{H}_{2} \mathrm{~S}$ exerts important biological actions in vascular smooth muscle cells. Originally $\mathrm{H}_{2} \mathrm{~S}$-induced vasorelaxation was believed to be mediated by potassium channels (including $\mathrm{K}_{\mathrm{ATP}}$ channels). However, significant vasodilation can be observed after sulfonylurea treatment, suggesting that additional pathways are involved. We recently showed that $\mathrm{H}_{2} \mathrm{~S}$ donors inhibit phosphodiesterase activity in vitro and that exposure to $\mathrm{H}_{2} \mathrm{~S}$ increases cGMP levels in smooth muscle cells. The cGMP elevating effects of $\mathrm{H}_{2} \mathrm{~S}$ are abolished following phosphodiesterase inhibition. Moreover, incubation of cells with $\mathrm{H}_{2} \mathrm{~S}$ led to an increase in VASP phopshorylation on Ser239, suggesting that $\mathrm{H}_{2} \mathrm{~S}$ activates PKG signalling pathways. More importantly, incubation of aortic rings with selective PKG-I inhibitors (DT-2, DT-3) attenuated $\mathrm{H}_{2} \mathrm{~S}$-induced vasorelaxation. Our results reinforce the notion that $\mathrm{H}_{2} \mathrm{~S}$ plays important roles in vascular biology, by modulating vascular growth and tone.

Published: 1 August 2011

doi:10.1186/1471-2210-11-S1-027

Cite this article as: Papapetropoulos: Regulation of vascular growth and tone by hydrogen sulfide. BMC Pharmacology 2011 11(Suppl 1):O27. 